\title{
VALIDAÇÃO DE CONTEÚDO PARA CONSTRUÇÃO DE SÍTIO VIRTUAL SOBRE USO DO BRINQUEDO NA ENFERMAGEM PEDIÁTRICA*
}

\author{
Amparito del Rocío Vintimilla Castro¹, Magda Andrade Rezende²
}

\begin{abstract}
RESUMO: O brincar possibilita cuidar da criança hospitalizada em situações ansiogênicas. Este estudo exploratório, quantitativo e qualitativo, realizado de abril de 2008 a abril de 2009, objetivou validar o conteúdo sobre uso do brinquedo na Enfermagem Pediátrica para construção de sítio virtual. Utilizou-se a Técnica Delphi e a escala Likert com valores de 5 a 1 ponto; o Coeficiente Alfa $(\alpha)$ de Cronbach $(\geq 0,7)$ mediu a consistência interna de três domínios com 24 ementas e a porcentagem $(\geq 70 \%)$ comparou a concordância entre 12 juízas. No primeiro ciclo levantou-se o julgamento dos três domínios propostos alcançando $\alpha$ de Cronbach de 0,96 . O segundo ciclo verificou $\alpha$ de Cronbach de 0,91 e mediu a propriedade e a clareza de 23 ementas. As sugestões foram agrupadas e analisadas para serem aceitas ou modificadas. Validou-se o conteúdo proposto embasado no atendimento às necessidades infantis. PALAVRAS-CHAVE: Jogos e brinquedo; Comunicação; Hospitalização; Enfermagem pediátrica.

\section{CONTENT VALIDATION FOR THE CONSTRUCTION OF A VIRTUAL SITE ON USE OF TOYS IN PEDIATRIC NURSING}

\begin{abstract}
Play makes it possible to care for the hospitalized child in anxiogenic situations. This exploratory, quantitative and qualitative study, undertaken between April 2008 and April 2009, aimed to validate the content on use of the toy in Pediatric Nursing for the construction of a virtual site. The Delphi Technique and the Likert scale were used, the latter with values from 1 to 5 points; the Cronbach alpha co-efficient $(\alpha)(\geq 0.7)$ measured the internal consistency of three dimensions with 24 elements and the percentage compared the agreement among 12 judges. In the first cycle, the judgment of the three domains proposed was surveyed, reaching a Cronbach $\alpha$ of 0.96 . The second cycle ascertained a Cronbach $\alpha$ of 0.91 and measured the property and the clarity of 23 elements. The suggestions were grouped and analyzed for them to be accepted or changed. The content proposed was validated, based on meeting the infants' needs. KEY-WORDS: Games and toys; Communication; Hospitalization; Pediatric nursing.

\section{VALIDACIÓN DE CONTENIDO PARA CONSTRUCCIÓN DE SITIO VIRTUAL SOBRE USO DEL JUGUETE EN LA ENFERMERÍA PEDIÁTRICA}

RESUMEN: El jugar posibilita cuidar del niño hospitalizado en situaciones ansiogénicas. Este estudio exploratorio, cuantitativo y cualitativo, realizado de abril de 2008 a abril de 2009, tuvo el objetivo de validar el contenido sobre el uso del juguete en la Enfermería Pediátrica para construcción de sitio virtual. Se han utilizado la técnica Delphi y la escala Likert con valores de 5 a 1 punto; el Coeficiente Alfa $(\alpha)$ de Cronbach $(\geq 0,7)$ midió la consistencia interna de tres dominios con 24 resúmenes y el porcentaje ( $\geq 70 \%$ ) comparó la concordancia entre 12 juezas. En el primer ciclo se analizaron los tres dominios propuestos, alcanzando $\alpha$ de Cronbach de 0,96. El segundo ciclo verificó $\alpha$ de Cronbach de 0,91 y midió la propiedad y la objetividad de 23 resúmenes. Las sugerencias fueron agrupadas y analizadas, siendo aceptas o cambiadas. Se validó el contenido propuesto embasado en el atendimiento a las necesidades infantiles.

PALABRAS CLAVE: Juegos y juguetes; Comunicación; Hospitalización; Enfermería pediátrica.

*Extraído de tese 'Validação de conteúdo de sítio virtual sobre uso do brinquedo na enfermagem pediátrica' apresentada à Escola de Enfermagem da Universidade de São Paulo - EE USP, em 2010.

${ }^{1}$ Enfermeira. Doutora em Ciências. Coordenadora do Serviço de Educação Permanente do Instituto da Criança do Hospital das Clínicas da Faculdade de Medicina da USP. Educadora em Diabetes. Membro do Grupo de Pesquisa Gerenciamento de Recursos Humanos: conceitos, instrumentos e indicadores do processo de dimensionamento de pessoal.

${ }^{2}$ Enfermeira. Professora do Departamento de Enfermagem Materno-Infantil e Psiquiátrica da EE USP. Membro do Grupo de Pesquisa História e Legislação de Enfermagem.

Autor correspondente:

Recebido: 25/09/2012

Amparito del Rocío Vintimilla Castro

Aprovado: 22/03/2013

Universidade de São Paulo

Rua Afonso Celso, 833 - 04119-060 - São Paulo-SP-Brasil

E-mail: amparito.castro@hc.fm.usp.br 


\section{INTRODUÇÃO}

A doença e a hospitalização podem desencadear crises na vida da criança, a depender da idade, experiências anteriores e tipo de apoio recebido da equipe que a assiste e da própria família. As situações desconhecidas, dolorosas ou desconfortáveis são fatores desencadeantes de ansiedade e medo ${ }^{(1)}$. Ao refletir sobre a assistência humanizada à criança, o enfermeiro pode utilizar o brinquedo, que possibilita criar um vínculo com a criança hospitalizada e sua família( ${ }^{(2)}$, sejam estes dramático ou catártico, instrucional e facilitador das funções biológicas de acordo com as necessidades de cada criança e, de acordo também, com o objetivo do enfermeiro durante a assistência à criança ou ao adolescente $^{(3)}$. Esta pesquisa teve por objetivo validar o conteúdo sobre uso do brinquedo na Enfermagem Pediátrica para construção de sítio virtual.

\section{MÉTODOS}

Estudo exploratório, descritivo de cunho quantitativo e qualitativo, realizado no período de abril de 2008 a abril de 2009. Utilizou-se a Técnica Delphi, em dois ciclos, que possibilita o julgamento de um grupo de especialistas em algum assunto ${ }^{(4)}$ e foi realizado no Departamento de Enfermagem Materno-Infantil e Psiquiátrica da Escola de Enfermagem da Universidade de São Paulo. Foram convidadas 14 juízas que atenderam aos seguintes critérios: trabalhar no Brasil, ter experiência em brinquedo, ter título de Mestre ou Doutor e ter publicações sobre brinquedo. Adotada a escala Likert ${ }^{(5)}$ para medir julgamentos, com valores decrescentes de 5 a 1 ponto: Completamente Adequado (CA), Adequado(a), Parcialmente Adequado (PA), Inadequado (I) e Completamente Inadequado (CI). Esta escala foi aplicada na elaboração de formulários que propunham ementas, originadas do levantamento bibliográfico e da experiência teórico-prática das pesquisadoras $^{(1-3 ; 6-12)}$. As ementas foram agrupadas em três domínios: 1- O brincar como estratégia de cuidado de Enfermagem Pediátrica; 2- O brincar terapêutico como estratégia de cuidado de Enfermagem Pediátrica; 3Comunicação terapêutica criança-enfermeiro durante as sessões de brinquedo. No primeiro ciclo avaliou-se a consistência interna do conteúdo das ementas utilizando o Coeficiente Alfa de Cronbach ${ }^{(13)}$ por meio de valores numéricos de 0 a 1 . O critério de corte do Alfa de Cronbach foi de $\geq 0,70$. Utilizada a porcentagem para comparar a concordância entre os juízes adotando- -se $\geq 70 \%$. No segundo ciclo, avaliou-se o consenso de opinião quanto à propriedade e a clareza por meio do Coeficiente Alfa de Cronbach ${ }^{(13)}$ com critério de corte $\geq 0,70$. As sugestões, em ambos os ciclos, foram analisadas para acatá-las ou não. Pesquisa aprovada pelo Comitê de Ética e Pesquisa da Escola de Enfermagem da Universidade de São Paulo sob n. 786/2008/ CEP-EEUSP segundo a Resolução n. 196/96 de 10 de outubro de 1996 do Conselho Nacional de Saúde ${ }^{(14)}$.

\section{RESULTADOS}

\section{Primeiro Ciclo Delphi}

As respostas emitidas por 12 juízas, com idades entre 35 a 60 anos incompletos, foram obtidas em cinco meses. Das 14 profissionais selecionadas, no âmbito do Brasil, somente duas não participaram, pois uma não chegou a responder ao convite e outra desistiu do estudo logo em seu início. Oito (66,8\%) juízas residiam e trabalhavam no Estado de São Paulo e uma (8,3\%) residia em cada um dos Estados do Ceará, Mato Grosso, Paraíba e Paraná. Onze (91,6\%) juízas eram Doutoras e uma, $(8,4 \%)$ Mestre. Onze $(91,6 \%)$ realizaram pós-graduação na área de Enfermagem Pediátrica e uma $(8,3 \%)$ em Psicologia. Nove (75\%) trabalhavam exclusivamente em instituição de ensino superior e oito $(66,7 \%)$ atuavam em ensino e em pesquisa.

As juízas procederam à avaliação de 24 ementas contidas em três Domínios:

Domínio 1 - Relacionado ao Brincar, estratégia de cuidado de Enfermagem Pediátrica. Constava de cinco ementas: 1.1-O brincar normativo ou recreacional e o brincar terapêutico na vida das crianças de 0 a 10 anos de idade. 1.2-O brincar como estratégia de cuidado de Enfermagem Pediátrica. 1.3-Brinquedotecas hospitalares. 1.4-Riscos/acidentes em brincadeiras. 1.5-Inclusão do brincar na Sistematização da Assistência de Enfermagem.

Cada uma das cinco ementas obteve um Coeficiente de Alfa de Cronbach de 0,96, superando o Alpha mínimo eleito $(\geq 0,70)$. Ao comparar e analisar as sugestões, juntou-se o item 1.5 ao 1.2; desmembrou-se a faixa etária de 0-10 anos, tanto para o brincar recreativo, quanto para o terapêutico; acrescentou-se o brinquedo recreacional aplicado a grupo de crianças; incluiu-se a participação da família na brincadeira.

Domínio 2 - Relacionado com o brincar terapêutico como estratégia de cuidado de Enfermagem Pediátrica. Continha seis ementas: 2.1-O brincar terapêutico em 
situações de dor, medo, restrições, procedimentos, rotinas incomuns. 2.2-Tipos de brincar terapêutico: catártico, instrucional e facilitador das funções biológicas. 2.3-O brincar dramático ou catártico. 2.4-O brincar instrucional. 2.5-O brincar facilitador das funções biológicas. 2.6-Inclusão do brincar terapêutico na Sistematização da Assistência de Enfermagem.

As seis ementas também alcançaram coeficientes de concordância Alpha de Cronbach de 0,96, maior do que o valor de corte $(\geq 0,70)$. Ao analisar as sugestões apontadas, incorporou-se: explorar o conceito de brinquedo terapêutico e seu objetivo; acrescentar que o brinquedo instrucional envolve atividade lúdica com adaptações das atividades segundo as necessidades da criança; esclarecer que o brincar dramático promove autoterapia; substituir a expressão "facilitador das funções biológicas" por "funções fisiológicas".

Domínio 3 - Relacionado com a comunicação terapêutica criança-enfermeiros. Contém treze ementas: 3.1-Conceito de comunicação; 3.2-Formas de comunicação: verbal e não verbal; 3.3-Importância da comunicação entre a criança e o adulto: possibilita compreensão das necessidades da criança pelo profissional; 3.4-Comunicação terapêutica; 3.5-Técnicas de comunicação terapêuticas como facilitadoras da comunicação; 3.6-Reflexão de sentimentos: consiste em dizer explicitamente ao outro os sentimentos subjacentes captados nas mensagens, que são enviadas; 3.7-Autoexpressão; 3.8-Confronto; 3.9-Estabelecimento de limites; 3.10-Redução dos impasses e conflitos; 3.11-Distribuição do poder; 3.12-Orientação antecipatória; 3.13-Reasseguramento da aprendizagem da confiança.

Tal como nos tópicos anteriores, os Coeficientes Alpha de Cronbach apontaram resultados entre 0,95 e 0,96 , considerados altos, maiores que o valor de corte $(\geq 0,70)$. As sugestões apontadas pelas juízas foram analisadas e acatadas, acrescentou-se a comunicação tacêsica, a comunicação simbólica e os sentimentos, além de necessidades da criança. Apesar de atingir coeficientes elevados de Alpha de Cronbach em todas as ementas, decidiu-se realizar um segundo ciclo, pois seria uma excelente oportunidade de se dialogar com as juízas e refinar ainda mais o conteúdo das ementas, valorizando o trabalho realizado nesta etapa.

\section{Segundo Ciclo Delphi}

Neste ciclo avaliou-se a propriedade e a clareza das ementas modificadas no Primeiro Ciclo utilizando o Coeficiente Alfa de Cronbach e considerou-se a utilização de linguagem clara, concisa, simples e de fácil compreensão. Tal como no primeiro ciclo, considerou-se valores $\geq 0,70$ como critério de corte. Para a propriedade e para a clareza das ementas, correspondentes aos três domínios obtiveram-se resultados de 0,90 e 0,91, respectivamente. Como não foi possível medir o efeito de eliminação de cada quesito pela homogeneidade dos dados, foi utilizada a porcentagem de concordância em cada um deles, atingindo-se valores acima de $70 \%$. Para a 'propriedade' obteve-se $100 \%$ de concordância para três itens, exceto o item 1.3 que resultou em $91,7 \%$. Para a 'clareza', foram apontados valores que variaram de $83,3 \%$ a $91,7 \%$ acima dos $70 \%$, previamente estipulado. Ao analisar as sugestões, foi apontado para ampliar o brinquedo para 12 anos; incluir o direito de brincar segundo o Estatuto da Criança e do Adolescente; frisar que a brinquedoteca no âmbito hospitalar colabora para o desenvolvimento físico, intelectual e social; destacar a importância da brincadeira na Política Nacional de Humanização e reforçar a comunicação terapêutica entre a criança e o profissional de saúde. Além disso, houve a sugestão de incluir alguns exemplos às ementas para esclarecê-las. Assim, elaboraram-se as ementas definitivas para desenvolvê-las em sítio virtual:

Domínio 1 - O brincar como estratégia de cuidado na Enfermagem Pediátrica. Abordaram-se as seguintes ementas: 1.1-Conceito de brincar. Funções do brinquedo. $\mathrm{O}$ brinquedo recreacional na vida das crianças de 0 a 12 anos. O brinquedo recreacional provê à criança socialização e prazer, por meio de atividades individuais ou em grupo. Direito da criança para brincar, segundo o Estatuto da Criança e do Adolescente e a Internacional Play Association. 1.2- O brincar como estratégia de cuidado de Enfermagem Pediátrica a fim de promover o desenvolvimento infantil, bem como a comunicação entre a criança e a equipe de enfermagem. Inclusão do brincar na Sistematização da Assistência de Enfermagem para garantir o brincar da criança durante a internação. 1.3- Definição de brinquedoteca hospitalar, espaços lúdicos que promovem o desenvolvimento físico, intelectual, emocional e social das crianças internadas. Sua importância na Política Nacional de Humanização. 1.4- Segurança na brincadeira e influência em cada etapa do desenvolvimento, co-responsabilidade dos familiares, após orientação da equipe de enfermagem para prevenir aspiração de objetos, intoxicação por ingesta, ferimentos, quedas, reações alérgicas, riscos microbiológicos.

Domínio 2 - O brincar terapêutico como estratégia de cuidado na Enfermagem Pediátrica. Abordaram-se as 
seguintes ementas: 2.1- Conceito e objetivos de brinquedo terapêutico. $\mathrm{O}$ brinquedo terapêutico na vida do pré-escolar e do escolar. O brinquedo terapêutico em situações ansiogênicas, tais como o desconhecido, o temor de mutilação e a perda de controle, comuns em assistência à saúde. Brinquedo terapêutico em situações de dor, medo, restrições, procedimentos, rotinas incomuns. Atividade lúdica planejada que possibilita à criança expressar seus sentimentos, fazendo-a reviver situações que a preocupam, assim como aprender e compreender, utilizando suportes adequados. 2.2-Tipos de brinquedo terapêutico: dramático ou catártico, instrucional e facilitador das funções fisiológicas. A modalidade, ou as modalidades necessárias, de acordo com as necessidades da criança. Escolha da modalidade segundo idade e necessidades das crianças. O brinquedo terapêutico utilizado de forma individualizada ou em grupo, com participação ou não do familiar. 2.3- O brinquedo dramático ou catártico auxilia a criança no controle de situações desconhecidas ou assutadoras, possibilita ao enfermeiro compreender o significado de suas vivências. 2.4-O brinquedo instrucional possibilita explicar à criança procedimentos, eventos, mudanças na imagem corporal e limitações fisiológicas. Utilizar linguagem compatível com a idade e nível de compreensão da criança, a fim de estimular sua autoconfiança e senso de segurança. 2.5- O brinquedo facilitador das funções fisiológicas consiste em adaptar atividades lúdicas para manter e melhorar a saúde física da criança. A escolha das atividades reforça e possibilita maior participação da criança no autocuidado e a capacita em termos fisiológicos. 2.6- Inclusão do brinquedo terapêutico na Sistematização da Assistência de Enfermagem. Possibilita ao enfermeiro assistir a criança, com maior eficácia, de acordo com suas necessidades. Competência legal do enfermeiro para o uso de brinquedo terapêutico.

Domínio 3 - Comunicação terapêutica. Contêm as seguintes ementas: 3.1-Conceito de comunicação: processo que envolve o emissor, o receptor e a mensagem, concatenados para compreender, compartilhar mensagens enviadas e recebidas, exercendo influência no comportamento das pessoas nele envolvidas, a curto, médio ou longo prazo. 3.2- Formas de comunicação: verbal e não verbal. A verbal consiste no uso da linguagem escrita e falada para expressar ideias e partilhar experiências com outras pessoas. A comunicação não verbal refere-se ao uso de expressões faciais, corporais e fisiológicas. A comunicação tacêsica consiste no uso do toque e pode ser utilizada em crianças menores, como lactente e pré-escolar que ainda não dominam a comunicação verbal. 3.3- Importância da comunicação entre a criança e o adulto: auxilia ao adulto compreender necessidades, sentimentos e conceitos da criança. Também possibilita à criança compreender o adulto no que diz respeito à suas intenções de cuidado, ou seja, o brinquedo enquanto comunicação simbólica. 3.4- Comunicação terapêutica: processo no qual o foco é a pessoa que está sendo cuidada, a fim de que seja compreendida nos seus sentimentos e emoções. 3.5Comunicação terapêutica: processo no qual o foco é a pessoa que está sendo cuidada, a fim de que seja compreendida nos seus sentimentos e emoções. 3.6- Reflexão de sentimentos: consiste em dizer explicitamente ao outro, se pertinente, os sentimentos subjacentes que se captam nas mensagens que são enviadas. Por exemplo: durante o preparo da criança para uma punção venosa, reconhecer que esta sente medo e que este é legítimo, pois possibilita entrar em sintonia com seu interior e transmite aceitação e compreensão. É a principal forma facilitadora de comunicação e da qual dependem todas as outras. 3.7- Auto expressão: consiste em expressar, de forma clara, ao outro, os próprios sentimentos. 3.8Confrontamento: é a aprendizagem do enfrentamento as consequências que certas atitudes provocam no outro e acentua os efeitos da aprendizagem. Por exemplo, quando a criança reage mordendo pode-se dizer que não deve fazê-lo, mas que se compreende seus sentimentos e que se busca alternativas para cuidá-la. 3.9- Estabelecer limites: ensina a criança, por meio de enunciados firmes e claros, o que é permitido ou proibido para protegê-la ou proporcionar-lhe segurança. Por exemplo: combinar com a criança, no início da atividade, quanto tempo esta vai durar, lembrando que, neste caso, deve haver flexibilidade. 3.10- Redução dos impasses e conflitos: direciona o comportamento da criança com vistas à otimizar seu cuidado. Por exemplo: quando a criança necessita hidratar-se e não o faz por pouco atraente e monótono, pode ser auxiliada com a brincadeira. 3.11Distribuição do poder: consiste na resolução conjunta de situações para possibilitar melhor cuidado à criança e favorecer seu desenvolvimento. Por exemplo: o momento da realização de um curativo pode ajudar a criança a participar do seu cuidado por meio do brinquedo terapêutico instrucional. Haverá distribuição do poder entre o profissional e a criança para possibilitar a terapêutica sensação de compartilhar responsabilidades. 3.12-Orientação antecipatória: prepara a criança para acontecimentos importantes por meio da orientação de situações futuras. Possibilita diminuição da inseguran- 
ça, da ansiedade e do medo do desconhecido, bem como facilita a ativação dos processos adaptativos da personalidade. 3.13- Reasseguramento da aprendizagem da confiança: consiste no alivio da ansiedade, temores ou dúvidas, seja pela falta ou distorção de informações ou pela presença de sentimentos de tristeza, culpa, autodepreciação e insegurança. Ajuda a criança a lidar com vivências intensas e assustadoras. Por exemplo: para a criança, a experiência de ter que se submeter a uma injeção pode ser assustadora, a ponto de causar-lhe sentimento de culpa e de autodepreciação. Para esta situação é indicado o brinquedo instrucional, lembrando que cada situação deve ser analisada individualmente. Antes de realizar a injeção, o profissional verbaliza à criança que tem liberdade para chorar e que isto não afetará a maneira como ela é vista. Este asseguramento é importante para preservar a autoimagem da criança. Se necessário, os pais também podem ser orientados a respeito deste fato, uma vez que o choro eventualmente não é aceito, especialmente quando relacionado a questões de gênero ou maturidade da criança.

\section{DISCUSSÃO}

A idade das juízas associa a experiência, capacidade de crítica social e autocrítica profissional, características que implicam em oportunidades de desenvolvimento e incremento de competências que se concretizam no bojo do processo técnico-científico $^{(15)}$. Estudos apontam abstenção de $30 \%$ a $50 \%$ dos respondentes no primeiro ciclo, e de $20 \%$ a $30 \%$ no segundo, apesar de que números altos de juízes nem sempre são indicadores de bons resultados ${ }^{(16)}$. Para obter consenso, o Coeficiente Alfa de Cronbach $^{(13)}$ permite medir a consistência interna entre os itens de um instrumento e comparar a concordância, entre os juízes, com valores numéricos de 0 a 1. Considerada maior consistência e confiabilidade quando os escores se aproximam de $1^{(13)}$. Em termos de porcentagem, o valor $\geq 70 \%$ é descrito, na maioria dos estudos encontrados na enfermagem brasileira, com variação de $50 \%$ a $90 \%{ }^{(16)}$.

A inserção do brincar como estratégia de cuidado de Enfermagem Pediátrica para complementar a Sistematização da Assistência de Enfermagem está prevista pelos Conselhos de Enfermagem que destacam a importância dos passos sistematizados e interrelacionados que permeiam a assistência ao paciente, por possibilitar reconhecer problemas e intervir com equidade, integralidade, individualidade e eficácia ${ }^{(17-18)}$. O direito de brincar e da recreação infantil é defendida e consolidada por órgãos nacionais e internacionais como a Declaração da International Play Association ${ }^{(12)}$, o Estatuto da Criança e do Adolescente $^{(11)}$ e a Política Nacional de Humanização(19). A aceitação do aumento da idade para utilizar o brinquedo recreativo e terapêutico ${ }^{(3)}$ para 12 anos vem ao encontro com o desenvolvimento gradual do adolescente com maior capacidade de manifestação verbal e relacionamento com outras pessoas ${ }^{(10)}$.

$\mathrm{O}$ brinquedo recreacional encoraja à brincadeira de forma prazerosa e espontânea, pode ser utilizado em grupo até com os familiares em brinquedotecas que permitem promover o bem estar físico, intelectual, social e emocional da criança que vivencia a hospitalização propiciando maior entendimento e segurança da família frente à terapêutica ${ }^{(20)}$. A cada estágio, o ser humano precisa enfrentar e superar um conflito central, ou seja, um grande desafio que deve ser resolvido para passar ao estágio seguinte. Este desafio surge não só de exigências internas de seu ego, mas também das exigências do meio ${ }^{(9)}$. O brinquedo terapêutico, seja este instrucional, dramático ou facilitador das funções fisiológicas, é uma atividade estruturada que promove a autoterapia da criança auxiliando-a no enfrentamento de situações hostis, permite dramatizar papéis e conflitos e faz um elo entre o mundo interior e exterior ${ }^{(3)}$. Também, alivia a ansiedade gerada por experiências desagradáveis, traumáticas ou ameaçadoras, esclarece conceitos errôneos, estimula a autoconfiança e pode ser utilizado para cada criança individualmente ou em grupos segundo objetivos do profissional e necessidades da criança ${ }^{(1,3,9)}$.

O brinquedo permite a comunicação simbólica, por meio de significados dos objetos utilizados, desvelando sua interioridade na brincadeira ${ }^{(9)}$. A comunicação tacêsica, relacionada com o toque, envolve a afeição e depende da aproximação entre as pessoas, do tempo, do local do toque e da pressão( ${ }^{(8)}$. A indissociabilidade da comunicação terapêutica entre a criança e o profissional de saúde reforça a assistência atraumática durante o processo de brincar e auxilia na percepção das necessidades infantis ${ }^{(3)}$. As crianças podem expressar e comunicar seus sentimentos de dor, medo, preocupação e insegurança, pois possibilita entender melhor suas necessidades ${ }^{(1,3)}$. A segurança dos brinquedos está regulamentada por normas técnicas para garantir a qualidade dos brinquedos por meio de testes que identificam possíveis riscos e avaliações ${ }^{(6)}$. 


\section{CONCLUSÕES}

A técnica Delphi confirmou sua aplicação na área de enfermagem, instrumentalizando a validação de conteúdo sobre a utilização do brinquedo pela Enfermagem Pediátrica, mesmo antes da construção de um sítio virtual. Esta pesquisa subsidiou a obtenção de consenso do conteúdo de três áreas temáticas cruciais para o cuidado entre o brincar como estratégia de cuidado de Enfermagem Pediátrica; o brincar terapêutico como estratégia de cuidado de Enfermagem Pediátrica e a comunicação terapêutica criança-enfermeiro. Estes conteúdos se transformam em programa de capacitação para enfermeiros da área pediátrica embasada no atendimento às necessidades infantis, no contexto temporal, geográfico e político da humanização das instituições hospitalares.

O conteúdo proposto nesta pesquisa tem relevância na educação, na humanização da assistência e contribui para a segurança no cuidado à clientela pediátrica. Neste contexto, pode auxiliar na elaboração de programas de treinamento segundo a realidade de cada instituição. Para promover o autoaprendizado e capacitação do enfermeiro, está previsto a construção de um sítio virtual institucional inserido na proposta de sistematização da assistência de enfermagem. Previamente, no endereço eletrônico: http://www.icr. usp.br, em Unidades Multiprofissionais, foi inserido um texto que ressalta a importância da utilização do brinquedo pelo enfermeiro durante a assistência, para estimular os profissionais a serem partícipes deste processo de humanização da assistência de enfermagem.

\section{REFERÊNCIAS}

1. Ribeiro C. Crescendo com a presença protetora da mãe: a criança enfrentando o mistério e o terror da hospitalização [tese]. São Paulo: Universidade de São Paulo; 1999.

2. Frota MA, Gurgel AA, Pinheiro MCDP, Martins MC, Tavares TANR. O lúdico como instrumento facilitador na humanização do cuidado de crianças hospitalizadas. Cogitare enferm. 2007;12(1):69-75.

3. Vessey J, Mahon M. Therapeutic play and hospitalized child. J Pediatr Nurs. 1990;5(5):328-33.

4. Williams P, Webb C. The Delphi technique: a methodological discussion. J Adv Nurs. 1994;19(1):180-6.

5. Marconi M, Lakatos E. Técnicas de pesquisa. São Paulo: Atlas; 2006.
6. Associação Brasileira de Normas Técnicas. NBR 11786: segurança do brinquedo - cancelamento e substituição. [Internet] 2004. [acesso em 16 ago 2010]. Disponível: http://www.abnt.org.br/Cancelamento/11786-Canc.pdf

7. SociedadeBrasileira de Pediatria(SBP). Direitos da Criançae do Adolescente Hospitalizados [Internet] 1995 [acesso em 21 mai 2008]. Disponível:http://www.direitosdacrianca.org.br/conanda/ resolucoes/resolucao-nb0-41- de-13-de-outubro-de-1995

8. Maldonado M. Comunicação entre pais e filhos. São Paulo: Integrare; 2008.

9. Erikson E. Childhood and society. New York: W Norton Company; 1993.

10. Brazelton T, Greenspan S. As necessidades essenciais das crianças. Porto Alegre: Artmed; 2002.

11. Brasil. Lei n. 8.069, de 13 de julho de 1990. Estabelece o Estatuto da Criança e do Adolescente [Internet] Brasília; 1990 [acesso em 16 ago 2010]. Disponível: http://www. planalto.gov.br/ccivil_03/Leis/L8069.htm

12. International Play Association (IPA). The IPA Declaration of a chid's right to play [Internet] [acesso em 16 ago 2010]. Disponível: http://www.ipausa.org/ ipadeclaration.html

13. Lee J. Coeficient Alpha and the internal structure of tests coeficient alpha and the internal structure of tests. Psychometric Society. 1951;16(3):297-334.

14. Ministério da Saúde (BR). Resolução 196/96. Diretrizes e Normas Regulamentadoras de Pesquisas Envolvendo Seres Humanos. Conselho Nacional de Saúde [Internet]. Brasília; 2012 [acesso em 15 mar 2012]. Disponível: http:// conselho.saude.gov.br/web_comissoes/conep/aquivos/ resolucoes/23_out_versao_final_196_ENCEP2012.pdf

15. Valente G, Viana L. Da formação por competências à prática docente reflexiva. Rev. iberoam cienc. tecnol. soc. 2009;48(4):1-7.

16. Castro A, Rezende M. A técnica Delphi e seu uso na pesquisa de enfermagem: revisão bibliográfica. REME: rev.min. enferm. 2008;13(3):429-34.

17. Conselho Regional de Enfermagem. Processo PRCI n. 51.669 de 24 de junho de 2004. Parecer fundamentado sobre utilização do brinquedo terapêutico pelo enfermeiro. São Paulo: COREN; 2004.

18. Conselho Federal de Enfermagem (COFEN). Resolução n. 295/2004. Dispõe sobre a utilização da técnica do 
brinquedo terapêutico pelo enfermeiro à na assistência à criança hospitalizada. [Internet] 2004 [acesso em 15 set 2008]. Disponível: http://site.portalcofen.gov.br/ node/4331

19. Ministério da Saúde (BR). Humaniza SUS: política nacional de humanização. A humanização como eixo norteador das práticas de atenção e gestão em todas as instâncias do SUS. Núcleo Técnico da Política Nacional de Humanização. [Internet] Brasília; 2004 [acesso em 11 nov 2010]. Disponível: http://bvsms.saude.gov.br/ bvs/publicacoes/humanizasus_2004.pdf

20. Brasil. Lei n. 11.104, de 21 de março de 2005. Dispõe sobre a obrigatoriedade de instalação de brinquedotecas nas unidades de saúde que ofereçam atendimento pediátrico em regime de internação. [Internet] Brasília; 2005 [acesso em 18 fev 2008]. Disponível: http://www. planalto.gov.br/ccivil_03/_Ato2004-2006/2005/Lei/ L11104.htm 